\title{
The Design and Application of Flip Classroom Teaching Based on Computer Technology
}

\author{
https://doi.org/10.3991/ijet.v13i10.9453 \\ Jia Li $(\varpi)$ \\ Hebei Agricultural University, Baoding, China \\ 24530329 @qq. com \\ Xiaoxia Zhang \\ Hebei North University, Zhangjiakou, China \\ Zijun $\mathrm{Hu}$ \\ Hebei Agricultural University, Baoding, China
}

\begin{abstract}
The promotion and application of computer technology in the education field has been driving the continuous innovation and development of traditional teaching methods. As a new type of blended learning model, flipping classroom can be well combined with computer technology to effectively improve the quality of education and teaching in colleges and universities. he Moodle provides a good network support platform for the implementation of flipping classroom. This paper aims to develop a new flipped classroom teaching model. Supported by Moodle and adhering to the philosophy of self-learning, this teaching model arranges learning tasks according to the different characteristics and needs of learners. Through interactions, it can develop students' self-learning abilities and improve their learning efficiency; through online tracking, it can understand students' learning dynamics in time and guide them in preview of knowledge points before class to allow them to think clearly. The purpose of this paper is to study the effects of the flipped classroom teaching method based on Moodle so as to find out what to improve in this model and make it widely applied in college teaching to cultivate more applied talents.
\end{abstract}

Keywords-Flipped classroom; modular; object-oriented; dynamic learning

\section{Introduction}

The classroom teaching models in colleges and universities have been continuously reformed with the rapid advancement of information technology. In many local junior and undergraduate colleges, more and more attention are being paid to the cultivation of applied talents, so relevant research has been carried out [1-3]. At present, the traditional education teaching model, due to its shortcomings, cannot satisfy the needs of colleges and universities for cultivation of applied talents, thus resulting in a serious shortage of applied talents in the society. Colleges and universities should constantly explore the reform of classroom teaching models, so that students will have sufficient 
autonomy and say in the classroom [4-6]. Flipped classroom, being in line with the requirements of modern education reform, has provided a reference method for colleges and universities to cultivate more applied talents. At present, there are still some problems in the practice of flipped classroom in colleges and universities. For example, the limited number of experiments conducted is not enough to explain its effectiveness, students have little practice of their operational skills, and there is a lack of an online education teaching platform [7-9]. Therefore, this paper establishes a flipped classroom teaching model based on the Moodle platform and forms a learning platform in the new context. The purpose is to focus on training students' comprehensive quality, improving their abilities to discover and solve problems and think independently and promoting their self-learning and self-practice skills so as to cultivate more applied talents in colleges and universities.

\section{Related theories and technologies}

\subsection{Flipped classroom}

Flipped classroom is also known as inverted classroom, whose core idea is to enable students to learn and absorb knowledge independently, and then deepen their understanding in the classroom, which can be summarized as learning and digesting before teaching [10-12]. Its essence is to combine the traditional teaching philosophy with the information-based teaching mode, which makes full use of the extensive information and teaching resources online and the network convenience. In this model, students can use electronic devices such as mobile phones to watch online micro-classes for selfstudy, and then deepen their understanding of knowledge in classroom [13-15]. Flipped classroom has an irreplaceable advantage in the modern teaching. It uses videos to present refined and rich teaching content, which provides new ideas for innovation of learning methods and breaks the space limitation of teaching.

\subsection{Moodle platform}

MOODLE, short for Modular Object-Oriented Dynamic Learning Environment, is a service platform that enables learners to learn autonomously, exchange knowledge and think independently [16-18]. Moodle can realize course management, and allow users to upload different courses to forums, chat rooms, blogs and other platforms and discuss them [19-20]. In addition, it also allows users to share resources like assignments and questionnaire surveys, adjust their schedule of course activities and information and select the teaching time to achieve openness of the teaching information. At the same time, teachers can check the students' homepage in the Moodle environment to understand their learning progress at any time and modify and improve their curricula accordingly. Moodle is in line with the needs of colleges and universities for flipped classroom education and also easy to operate, free of charge and open, making it a world-renowned curriculum management system. Now Moodle is becoming more 
and more well-known in the education field in China and has been generally recognized by educational experts.

\section{Construction of the flipped classroom teaching model based on the Moodle platform}

\subsection{Flipped classroom teaching model}

At present, the inter-conversion of the learning content in and outside class is the main educational method adopted in flipped classroom. Since the ancient times, the learning tradition has been carried on in China, where teachers teach knowledge in class and students digest and understand the knowledge by completing homework or practice outside class. Flipped classroom, unlike the traditional method, allows students to learn knowledge online with the aid of electronic equipment to train their independent thinking and problem finding abilities, and then discuss the problems by themselves in class to find the solutions. Tab. 1 shows the differences between a traditional class and a flipped class:

Table 1. Comparative analysis table of traditional classroom and flipped classroom

\begin{tabular}{|l|l|l|}
\hline \multicolumn{1}{|c|}{ Teaching elements } & \multicolumn{1}{c|}{ Traditional classroom } & \multicolumn{1}{c|}{ Flipped classroom } \\
\hline Teaching objectives & Subject knowledge & Learning ability \\
\hline Teaching form & Classroom information transmission & Information transfer before class \\
\hline Class content & Knowledge explanation, infusion teaching & Watch video for questions \\
\hline Teaching process & Teacher teaching, students learning & $\begin{array}{l}\text { Self-directed learning finds prob- } \\
\text { lems and leads to solutions }\end{array}$ \\
\hline Technology platform & Projection display content & Network teaching platform \\
\hline Teaching evaluation & Focus on academic performance & Focus on the learning process \\
\hline
\end{tabular}

\subsection{Flipped classroom model in the Moodle environment}

By referring to the educational philosophies of flipped classroom, this paper puts forward the concept of micro-class and establishes a teaching model based on Moodle, which combines the Moodle platform with the flipped classroom to maximize the advantages of both so as to better serve the learners. Fig. 1 shows the model, which mainly consists of the following modules:

In the pre-class guidance module, teachers record the class in the form of video and post it to the micro-class community section of the Moodle platform, along with a task list for pre-class preparation. According to this list, students can watch the video with directed attention and take notes in time, mark the knowledge points and digest and absorb them after class. The biggest advantage of this module is that students can conduct selective learning according to their own timetables. Before class, students will receive the courseware and the learning schedule so that they can choose the appropriate time to preview the course content. 


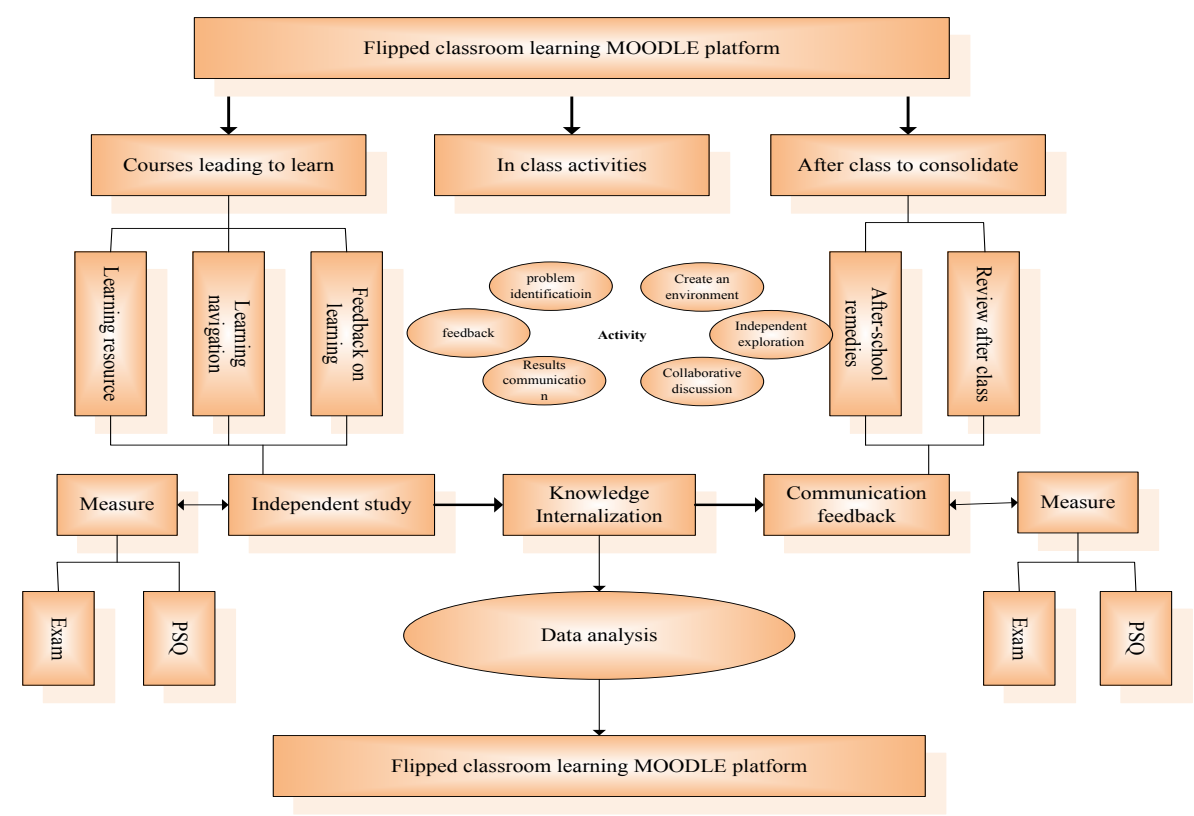

Fig. 1. Flipped classroom model in the Moodle environment

The in-class activity module is used for the process of learning and communication in the class. After previewing the content of a lesson, students summarize the problems found and then exchange and communicate with group members or teachers in different ways to find the solutions by themselves. This is to cultivate their abilities to explore independently.

In the after-class knowledge supplement module, the students rethink about the problems and deepen their understanding after class, and then summarize the knowledge points. They are also allowed to share their learning experience on the blogs on the Moodle platform to help each other digest knowledge.

\subsection{Flipped classroom teaching design in the Moodle environment}

The preparation of teaching content is an important precondition for flipped classroom, and also the basis for achieving teaching effects. So in order to give a class normally, it is necessary to fully prepare the content of the class.

Design of pre-class learning activities. The flipped classroom has its own teaching model. Students complete learning mainly through classroom teaching videos on the Moodle platform. The videos should target the learners' own characteristics. The key points and difficult parts should be clearly marked, and the duration of each video should be within 20 minutes. In this flipped classroom teaching model, teaching videos provided on the Moodle platform are the main way in which the course content is presented. In the Moodle environment, the model is divided into the following major modules, namely guidance and feedback, micro-class section, learning task list, self- 
evaluation and mutual evaluation and chat room, etc. Students can watch the teaching videos and complete the corresponding pre-class exercises. Teachers can mark the students' homework and check their learning task lists on the Moodle platform to understand their progress in learning and then based on this, help students discover and solve the difficulties they have encountered. The chat room on the Moodle platform is a place where students can communicate and discuss with each other to solve their questions they encounter during the learning process, as shown in Fig. 2:

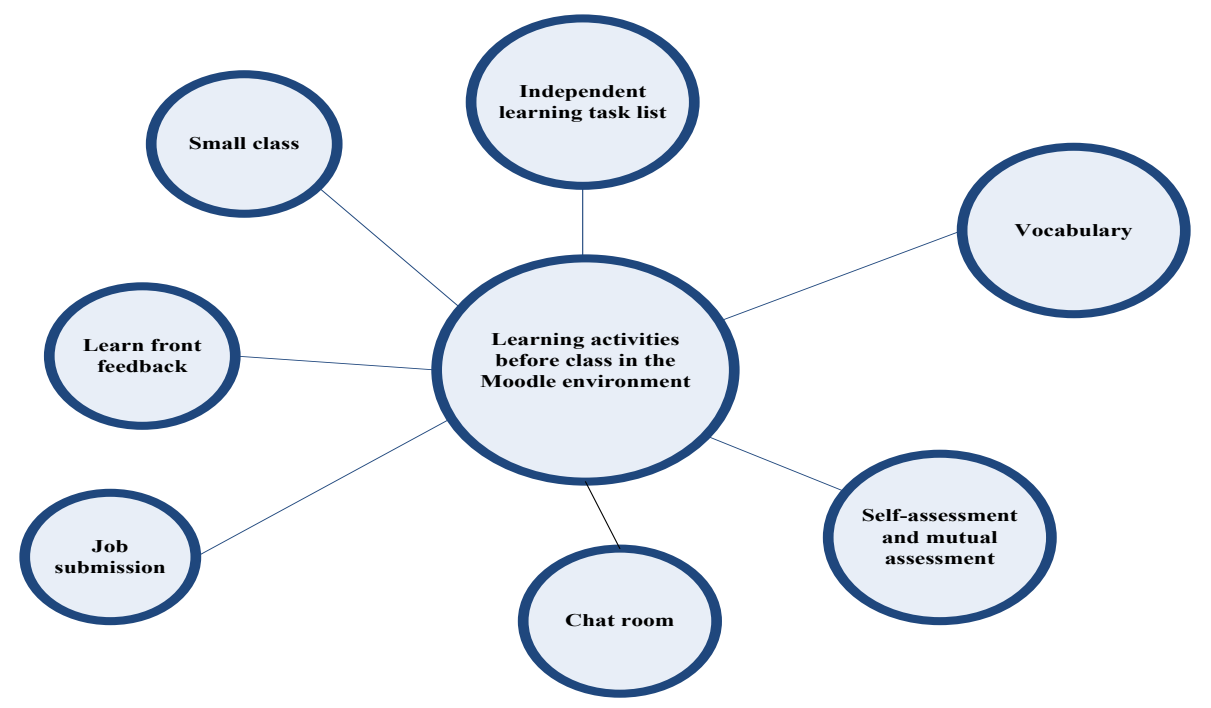

Fig. 2. Before learning module in Moodle

Design of in-class knowledge internalization activities. The first stage of the class is the feedback of questions. The Moodle platform retains the progress of the learners and the discussion of the questions. The feedbacks from students and the tracking survey of their learning progress can help teachers understand the problems students have encountered in a centralized manner so as to give general guidance. In addition, teachers can also provide individual tutoring for students according to their different problems. In the class, teachers adopt novel teaching methods and vivid teaching techniques, which greatly improves students' interest and enthusiasm in learning. See Fig. 3 for the detailed structure.

Design of after-class self-reflection and evaluation activities. After class is over, students can further consolidate their knowledge and deepen their understanding by doing the extended exercises. Teachers can evaluate students according to their learning progress on the platform, encourage students to learn from each other, and adopt different tutoring methods for different students. 


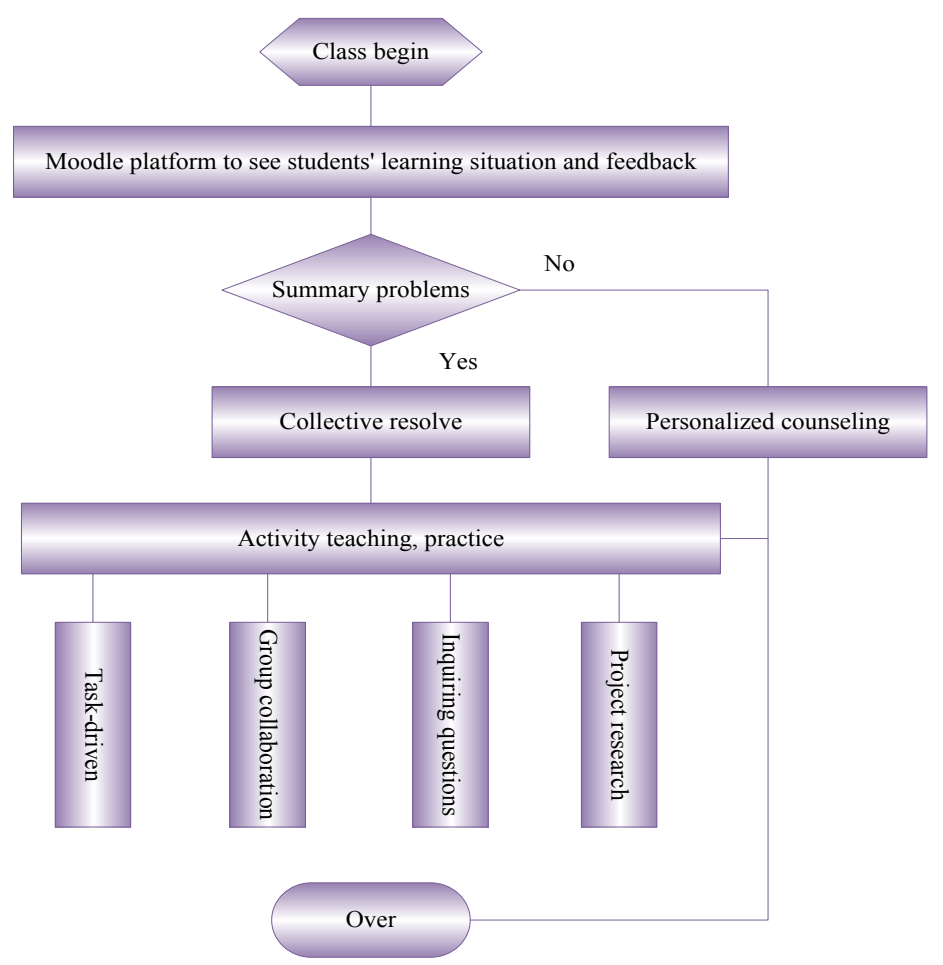

Fig. 3. Knowledge internalization activity structure design drawing

\section{Design and implementation of the Moodle-based flipped classroom learning platform}

\subsection{Design objectives and principles}

1. Overall design objectives:
(a) High-quality teaching resources and timely release of students' learning dynam- ics and test questions;
(b) Tracking and feedback of learning effects;
(c) Unique collaborative learning space;
(d) Novel evaluation model.

2. Design principles
(a) Student-centered and teacher-led;
(b) Sharing of network resources;
(c) Diverse teaching models;
(d) User interactivity. 


\subsection{Analysis of system requirements}

Based on the flipped classroom education and teaching model, this paper proposes several suggestions on strengthening network platform in terms of administrator, teacher and student:

1. Administrator: the administrator has the highest authority on the system to better manage different sections, users and resources.

2. Teacher: after being authorized by the administrator, the teacher can modify and edit the content of the course, check the learning dynamics of the students, and administer the learning-related posts and teaching videos.

3. Student: after registration, students can log into their own accounts and enter the main interface, where they can select to watch teaching video, discuss courses and upload homework.

\subsection{System function design}

This paper fully studies the initial needs of the flipped classroom system. According to the classroom requirements and the purposes of curriculum design, the overall functional diagram of the system is obtained.

1. Functional design for students. In this system, the functions for students including watching teaching videos, posting their views, conducting personal information and homework management, taking pre-class tests, checking and verifying information and completing related questionnaires.

2. Functional design for teachers. Teachers play an important role in the flipped classroom teaching model, so they are given high requirements in this system design. To support the "teacher-led" concept, the system should have the following functions: course management, questionnaire survey, information inquiry, personal information, chat room management, resources management, homework assignment, test management, database management and chat management.

3. Functional design for administrator. The administrator has the administrative rights to administer the Moodle page of the users and the related announcements issued by the learners, review the contents of different sections, and make timely revisions to the announcements. The administrators have authorities to manage settings, courses, logs and files.

\subsection{Database design}

The design of the database is the most important part of the system. The database should be able to integrate resources, testing and homework discussion data. The design elaborated in this paper mainly includes related concepts and data tables.

Conceptual structure design. Conceptual structure design is the most important part of database design, which mainly includes information modeling. E-R is a commonly used model. The E-R diagram of this system is shown in Fig. 4: 


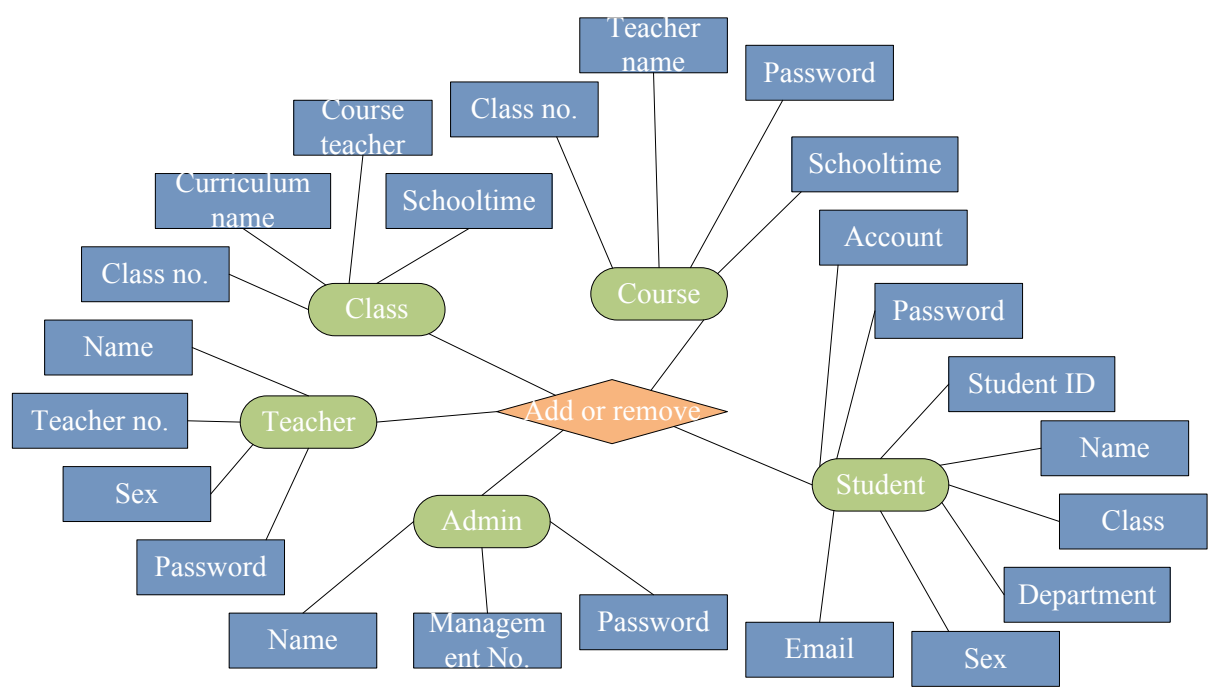

Fig. 4. The global E-R diagram of Moodle platform

Basic datasheet design. The database design of the Moodle system sets the corresponding primary keys by establishing the system tables, and sets the corresponding index with the relationships between the data tables. Tab. 2 is a data table in the system.

Table 2. The database tables involved in this system

\begin{tabular}{|c|c|}
\hline Data table & Function \\
\hline Admin & Administrator information \\
\hline Teacher & Teacher information \\
\hline Student & Student information \\
\hline Course & Course information \\
\hline Classes & Classes information \\
\hline Material & Learning information \\
\hline
\end{tabular}

\section{Implementation of the Moodle-based flipped classroom learning platform and teaching evaluation}

\subsection{Configuration and setup of the Moodle development environment}

The basic language of Moodle is PHP. Moodle cannot be operated without the support of important software, such as servers, PHP environment and database services. This paper selects the development kit downloaded from the official website of Moodle to set up the platform. 


\subsection{Key technologies of Moodle secondary development}

The online teaching is carried out in the context of a wide-area network. In order to better carry out teaching and provide more convenience, this system uses the B/S mode to maximize the use of the browser technology. Fig. 5 is the overall structure diagram:

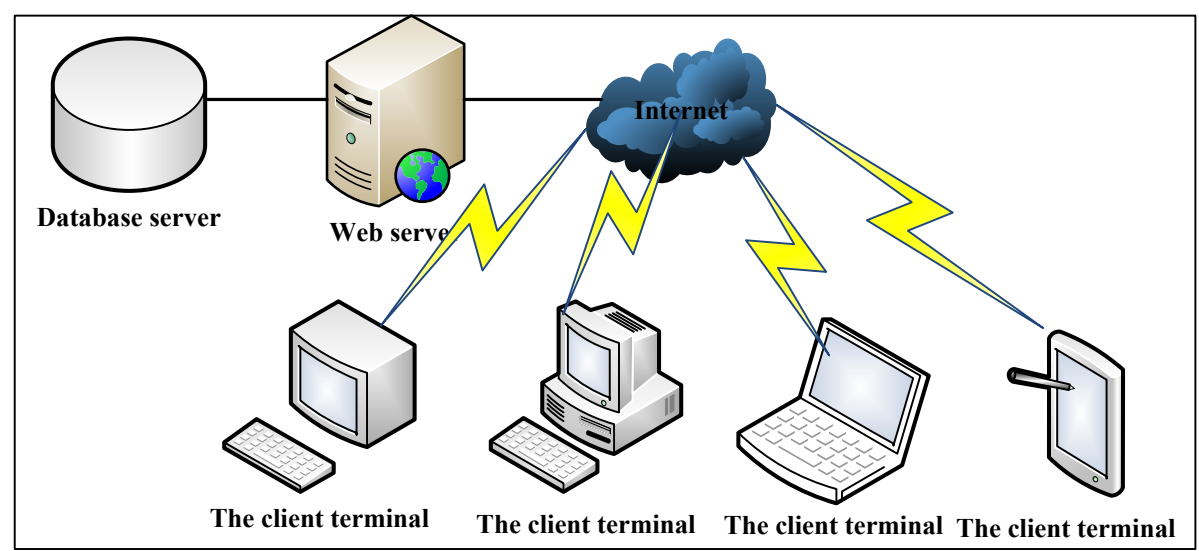

Fig. 5. The overall architecture of the system

The folder Theme is used to save the themes of Moodle. Different folders have different themes, so writing the code of each file is to develop the theme. Relevant codes are as follows:

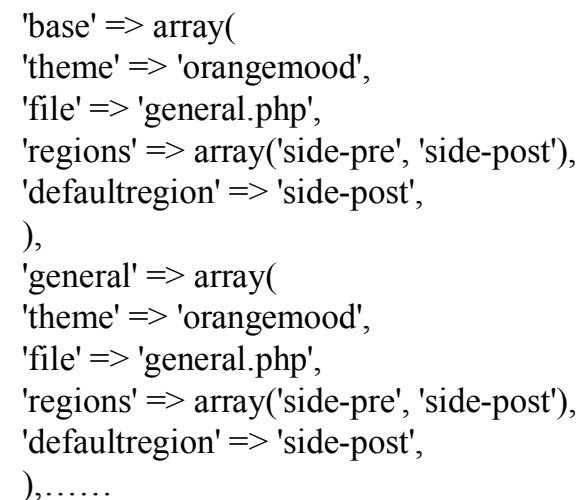

\subsection{Implementation of the Moodle main interfaces}

The Moodle platform will enter different interfaces according to the specific operator. Click the shortcut button of "Login the site" on the main page, the login page of the teaching platform will automatically pop up, presenting two different login methods, namely "sign up for a new account" and "browse as a visitor". The specific interface is shown in Fig. 6: 


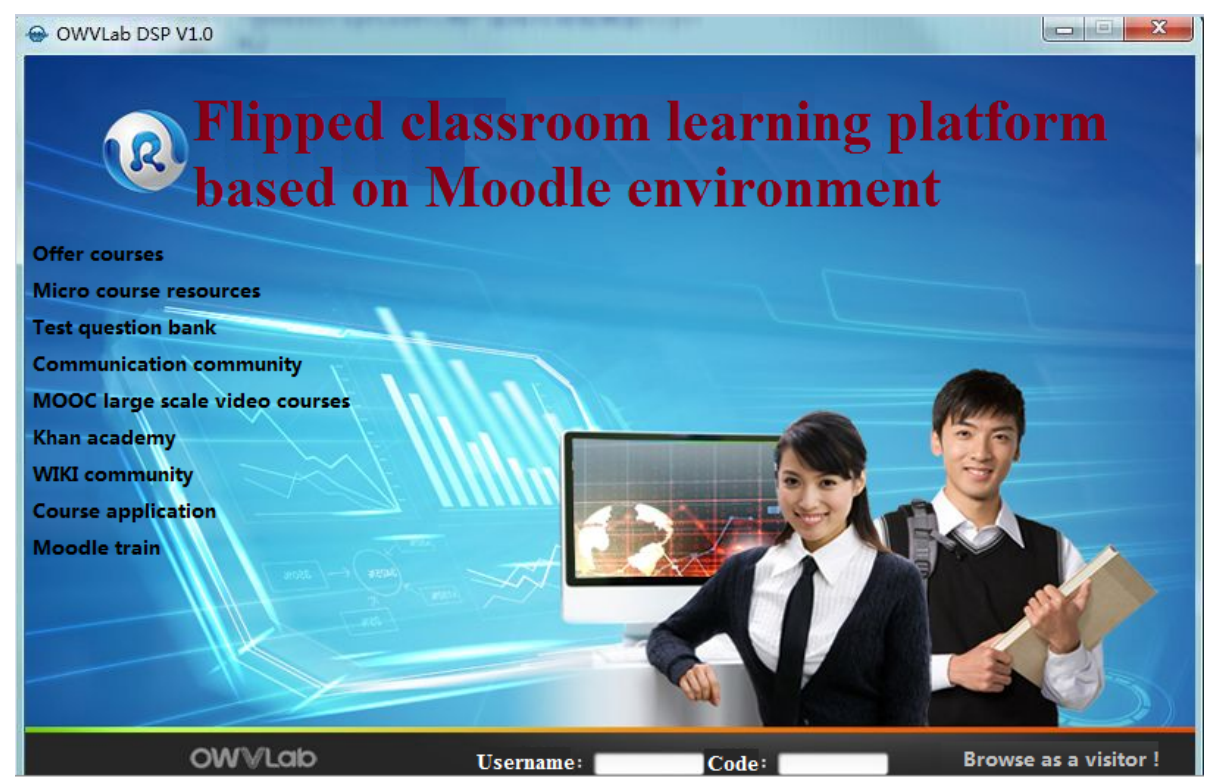

Fig. 6. Flipped classroom learning platform based on Moodle environment

This module has the function of protecting the security of user information. It can identify unauthorized users and restrict their login. Users who have already registered can only use their own accounts and passwords for authentication. In addition, users can also modify their own information, such as profile photo.

\subsection{Effectiveness evaluation}

There are generally two criteria for the evaluation of educational effects, namely the learning process and the result. Students' enthusiasm in participation and learning abilities and how they master the knowledge are part of the learning process, while the grade evaluation outside class is part of the learning result. The statistical results regarding the advantages of the flipped classroom teaching method are shown in Fig. 7: 


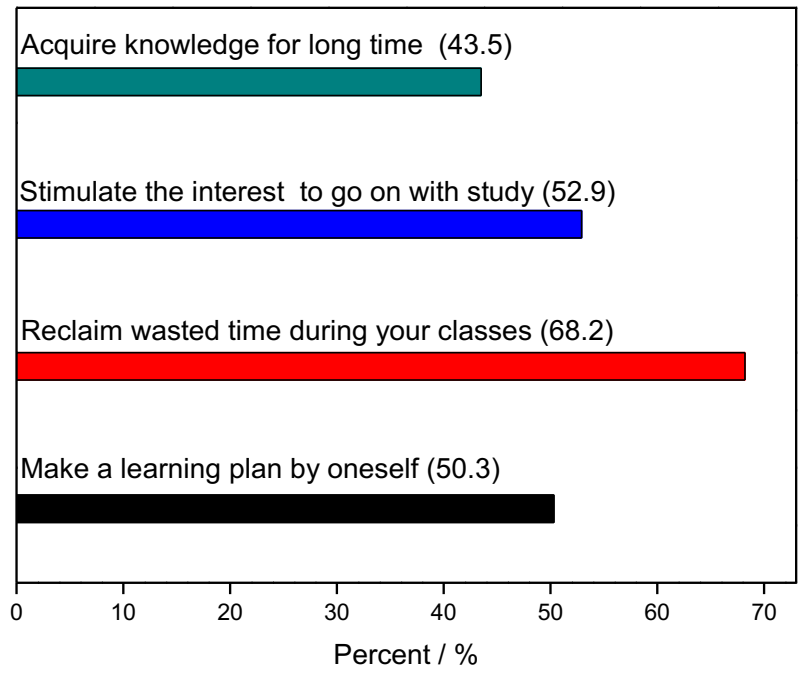

Fig. 7. Statistical learning advantages

Through the flipped classroom teaching model, $50.3 \%$ of the students increased their initiatives in learning. In addition, $68.2 \%$ of them improved their practical abilities through classroom teaching; $52.9 \%$ developed a great interest in learning; and $43.5 \%$ improved their understanding of the knowledge points through this model. Therefore, the flipped classroom teaching method based on the Moodle platform is very effective.

\section{Conclusions}

1. This paper establishes a flipped classroom teaching model based on Moodle and conducts in-depth studies on this model, providing a reference for the application of flipped classroom.

2. Through the functions of the Moodle platform and the flipped classroom concept, this paper designs and modifies the flipped classroom learning platform based on Moodle, which well integrates online teaching and flipped classroom to improve related services.

3. At last this paper verifies the various factors in the Moodle environment, and the verification results show that the flipped classroom can arouse students' learning interest more than the traditional method. It can help continuously cultivate students' comprehensive quality, including their understanding of knowledge as well as problem-finding and problem-solving abilities. 


\section{$7 \quad$ References}

[1] Wang, F. H. (2017). An exploration of online behaviour engagement and achievement in flipped classroom supported by learning management system. Computers \& Educa-tion, 114, 79-91. https://doi.org/10.1016/j.compedu.2017.06.012

[2] Li, D., Jiang, B., Li, H., \& Liu, X. (2016). Design of experiment course "computer-aided landscape design" based on flipped classroom. Computer Applications in Engi-neering Education, 24(2), 234-240. https://doi.org/10.1002/cae.21701

[3] Hew, K. F., \& Chung Kwan, L. O. (2018). Flipped classroom improves student learn-ing in health professions education: a meta-analysis. Bmc Medical Education, 18(1), 38. https://doi.org/10.1186/s12909-018-1144-Z

[4] Çırak Kurt, S., \& Yıldırım, İ. (2018). The students' perceptions on blended learning: A Q method analysis. Educational Sciences: Theory \& Practice, 18(2), 427-446. https://doi.org/10.12738/estp.2018.2.0002

[5] Girgis, F., \& Miller, J. P. (2018). Implementation of a "flipped classroom" for neuro-surgery resident education. Canadian Journal of Neurological Sciences, 45(1), 76-82. https://doi.org/10.1017/cjn.2017.234

[6] Lo, C. K., Chi, W. L., \& Hew, K. F. (2018). Applying "first principles of instruction" as a design theory of the flipped classroom: findings from a collective study of four secondary school subjects. Computers \& Education, 118, 150-165. https://doi.org/10.1016/j.comp edu.2017.12.003

[7] Pienta, N. J. (2016). A "flipped classroom" reality check. Journal of Chemical Educa-tion, 93(1), 1-2. https://doi.org/10.1021/acs.jchemed.5b00996

[8] Sharma, N., Lau, C. S., Doherty, I., \& Harbutt, D. (2015). How we flipped the medical classroom. Medical Teacher, 37(4), 327-330. https://doi.org/10.3109/0142159X.20 14.923821

[9] Herbert, C., Velan, G. M., Pryor, W. M., \& Kumar, R. K. (2017). A model for the use of blended learning in large group teaching sessions. Bmc Medical Education, 17(1), 197. https://doi.org/10.1186/s12909-017-1057-2

[10] Smith, C. M., \& Mcdonald, K. (2013). The flipped classroom for professional devel-opment: part ii. making podcasts and videos. Journal of Continuing Education in Nursing, 44(11), 486-487. https://doi.org/10.3928/00220124-20131025-93

[11] Betihavas, V., Bridgman, H., Kornhaber, R., \& Cross, M. (2016). The evidence for 'flipping out': a systematic review of the flipped classroom in nursing education. Nurse Education Today, 38, 15-21. https://doi.org/10.1016/j.nedt.2015.12.010

[12] Mcdonald, K., \& Smith, C. M. (2013). The flipped classroom for professional devel-opment: part i. benefits and strategies. Journal of Continuing Education in Nursing, 44(10), 437. https://doi.org/10.3928/00220124-20130925-19

[13] Kurup, V., \& Hersey, D. (2013). The changing landscape of anesthesia education: is flipped classroom the answer?. Current Opinion in Anesthesiology, 26(6), 726. https://doi.org/10.1097/ACO.0000000000000004

[14] Critz, C. M., \& Knight, D. (2013). Using the flipped classroom in graduate nursing ed-ucation. Nurse Educator, 38(5), 210-213. https://doi.org/10.1097/NNE.0b013e3182a0e56a

[15] Mortensen, C. J., \& Nicholson, A. M. (2015). The flipped classroom stimulates greater learning and is a modern 21st century approach to teaching today's undergraduates. Journal of Animal Science, 93(7), 3722-3731. https://doi.org/10.2527/jas.2015-9087

[16] Tan, E., Brainard, A., \& Larkin, G. L. (2015). Acceptability of the flipped classroom approach for in-house teaching in emergency medicine. Emergency Medicine Austral-asia, 27(5), 453-459. https://doi.org/10.1111/1742-6723.12454 
[17] Leung, J. Y., Kumta, S. M., Jin, Y., \& Yung, A. L. (2014). Short review of the flipped classroom approach. Medical Education, 48(11), 1127. https://doi.org/10.1111/medu. 12576

[18] Ryan, M. D., \& Reid, S. A. (2016). Impact of the flipped classroom on student perfor-mance and retention: a parallel controlled study in general chemistry. Journal of Chemical Education, 93(1). https://doi.org/10.1021/acs.jchemed.5b00717

[19] Rui, Z., Lian-Rui, X., Rong-Zheng, Y., Jing, Z., Xue-Hong, W., \& Chuan, Z. (2017). Friend or foe? flipped classroom for undergraduate electrocardiogram learning: a ran-domized controlled study. Bmc Medical Education, 17(1), 53. https://doi.org/10.1186/s12909-017-0881$\underline{8}$

[20] Lin, Y., Zhu, Y., Chen, C., Wang, W., Chen, T., \& Li, T., et al. (2017). Facing the challenges in ophthalmology clerkship teaching: is flipped classroom the answer?. Plos One, 12(4), e0174829. https://doi.org/10.1371/journal.pone.0174829

\section{Authors}

Jia Li, is a Master of Hebei University and a lecturer at Humanities and Social Sciences Academy, Hebei Agricultural University, Baoding 071001, China, mainly engaged in procedure law and agricultural law.

Xiaoxia Zhang, is a lecturer at Humanities and Social Science Academy, Hebei North University, Zhangjiakou 075000, China, mainly engage in musicology teaching.

Zijun Hu, is a Master of Hebei University and an associate professor at Humanities and Social Sciences Academy, Hebei Agricultural University, Baoding 071001, China, mainly engaged in procedure law and agricultural law.

Article submitted 14 July 2018. Resubmitted 13 August 2018. Final acceptance 10 September 2018. Final version published as submitted by the authors. 